\title{
HISTOPATHOLOGICAL AND BIOCHEMICAL STUDY ABOUT THE CHRONIC ADMINISTRATION OF BISPHENOL A ON THE GENITAL TRACT OF ADULT FEMALE ALBINO RATS
}

\author{
By \\ Mohamed Mahmoud Hussein, Fouad Helmy El-Dabah, Mohammed \\ Fathy Assasa, Al-Sayed Mohammed Ibrahim Tealeb* and Mohammed \\ Ali Abd El-Hamed \\ Departments of Forensic Medicine \& Clinical Toxicology, and Pathology*, Faculty of \\ Medicine, Al-Azhar University \\ Corresponding author: Mohamed Mahmoud Hussein, \\ E-mail: mohamedhussein_122@gmail.com
}

\begin{abstract}
Background: Bisphenol A (BPA) is an industrial chemical synthesized by condensation of two phenol groups and one acetone molecule. Sources of exposure to bisphenol A including food especially canned food, dust, papers especially thermal because it comes with food or due to recycling with other types of paper, dental materials, medical devices and healthcare applications. In rodents and primates, as well as humans, orally administered bisphenol A is rapidly and efficiently (95\% of dose) absorbed from the gastrointestinal tract and undergoes extensive first-pass metabolism in the gut wall and in the liver. During this first-pass metabolism, biotransformation of bisphenol A to bishenol A - glucuronide is the major pathway of BPA metabolism.
\end{abstract}

Objective: To demonstrate the possible chronic toxic effect (biochemical \& histopathological) of Bisphenol A on ovaries, uterus and vagina of adult female albino rats.

Materials and methods: The present study was conducted at the Animal House (Assiut University), and Departments of Forensic Medicine \& Clinical Toxicology and Pathology, Faculty of Medicine, Al-Azhar University, Egypt. The study followed the research ethics and standard protocol of dealing with animal. This research has been conducted on one hundred adult healthy female albino rats of a local strain weighing 100 120, during the period from April 2018 to May 2019.

Results: The chronic BPA exposure affected the pituitary gland, ovaries uterus and vagina of adult female albino rats. This effect appeared as significant statistical decrease in the total body weight of the rats. Biochemical examination revealed significant statistical decrease in serum levels of Follicular Stimulating Hormone (FSH), Luteinizing hormone (LH) and Estrogen. In addition, histopathological examination showed changes in the pituitary gland (cells showed disturbance in their architecture, hemorrhage and necrosis), ovary (disruption of the Graafian follicles, atretic follicles, dilated congested blood vessels and hemorrhage), uterus (severe degeneration and necrosis of the surface epithelium, leukocytic infiltration in the interstitial tissue, cystic dilation of endometrial glands, hyperplasia of endometrial epithelium and leukocytic infiltration with vacuolar degeneration in endometrial epithelium), and vagina (severe keratinization, epithelial atrophy, in addition to focal patches of decreasing of epithelial lining) when stained by hematoxylin and eosin stain then examined by light microscope.

Conclusion: The previous results proved the chronic toxic effects of BPA on the female reproductive system. So, the exposure to BPA that present in plastic containers and other products produces toxic effect on the reproductive health of females. 
Keywords: Bisphenol A, Pituitary Gland, Genital Tract of Adult Female Albino Rats.

\section{INTRODUCTION}

Bisphenol $\mathrm{A}$ is a synthetic compound classified as an endocrine disrupting chemical. It was first produced in 1891, but did not become commonly used until around 1930 when scientists added it to plastic to create polycarbonate plastic (Rubin, 2011).

Polycarbonate plastic, which is clear and temperature resistance, is used to make a variety of common products including baby and water bottles, feedingbottles, plates, goblets, cups, microwave ovenware, drink containers, the lining of water pipes, sports equipment, medical and dental devices, dental fillings sealants, CDs and DVDs, household electronics, eyeglass lenses and building materials (Geens et al., 2011).

Epoxy resins are the second largest end use of BPA which used as internal coatings on the inside of almost all food and beverage cans to prevent the direct contact of food with metal cans and to ensure their thermal stability and mechanical strength. Therefore, BPA can migrate into food depending upon food temperature, heating time, and physicochemical characteristics ('́wiek-Ludwicka and Ludwicki, 2014).

Braun et al. (2011) found significantly higher urinary BPA levels in women who consumed at least once a day canned vegetables as compared to those who consumed no canned vegetables at all.

Because of its widespread use and unlimited presence in the environment, the potential risk for human exposure to BSA is high. Since BPA showed estrogenic properties in a large number of studies, it is described as an endocrine disruptor chemical (EDC) (Chapin et al., 2011).

Peretz et al. (2014) concluded that BPA is a reproductive toxicant based on findings from experimental and epidemiological studies, with strong evidence that BPA is an ovarian toxicant in human females and animal models.

Animal studies indicate that BPA exposure causes abnormal estrous cyclicity, ovarian and uterine functions including steroidogenesis, follicular formation and oocyte production (Ziv-Gal and Flaws, 2016).

In 2017, the European Chemicals Agency concluded that BPA should be listed as a substance of very high concern due to its properties as endocrine disruptor (Mirmira and Evans-Molina, 2014).

The present study was conducted to demonstrate the possible chronic toxic effect (biochemically and histopathologicaly) of Bisphenol $\mathrm{A}$ on ovaries, uterus and vagina of adult female albino rats.

\section{MATERIALS AND METHODS}

The present study was conducted on female albino rats at the Animal House (Assiut University), and Departments of Forensic Medicine \& Clinical Toxicology and Pathology, Faculty of Medicine, AlAzhar University, Egypt during the period from April 2018 to May 2019.

\section{A. Materials:}

1. Drugs: Bisphenol A compound $99.9 \%$ purchased from Sigma Company. 
2. Chemicals and kits: Corn oil a vehicle purchased from ARMA Co. Egypt. Absolute ethyl alcohol (100\%) purchased from El Naser pharmaceutical Chemical Co., Egypt. Diethyl ether for anesthesia purchased from El Naser pharmaceutical Chemical Co., Egypt. Formalin 10\% purchased from Misr CO. Pharma, Egypt. Paraffin wax purchased from El Naser pharmaceutical Chemical Co. Egypt. Hematoxyline and Eosine stain purchased from Sedico Co. Egypt. Kits for determination of serum Follicular Stimulating Hormone (FSH), Luteinizing hormone (LH) and Estrogen (E2) purchased from Pishtaz Teb Diagnostics Company, Iran.

\section{Instruments:}

a. Containers: Vacutainer tubes $(5 \mathrm{ml}$ capacity) for collection of blood sample purchased from Elgomhouria co. Egypt. Automatic micropipettes $20^{\mu l}$, Huawie, made in china with disposable tips. Plastic container for storage of slides purchased from Al-Gomhouria co. Egypt. Glass container for storage of samples purchased from AlGomhouria co. Egypt. Gavage tube purchased from Al-Gomhouria co. Egypt. Cages for housing of animals purchased from Al-Gomhouria co. Egypt, (60 X 40 X $25 \mathrm{~cm})$.

b. Centrifuge: Centrifuge Universal 16 A, Hellich Zentrifugen, type 1601, 230/240V, made in Germany.

c. Enzyme-linked Immunosorbent Assay (ELISA): Using ELISA reader stat fax 3000 (Diagnostics Systems Laboratories, Webster, TX,
U.S.A) in department of Forensic Medicine and Clinical Toxicology, Faculty of Medicine, Assiut University.

4. Experimental animals: Ninety two (92) adult healthy female albino rats of local strain weighing $100-120 \mathrm{~g}$ were obtained from the animal house, Faculty of Medicine, Assiut University, Egypt.

\section{B. Methods:}

\section{Experimental design:}

The animals were housed in a clean capacious macro-lane cages $(60 \mathrm{X} 40 \mathrm{X}$ $25 \mathrm{~cm}, 5$ rats per cage), isolated from males, under standard laboratory conditions including good aerated room with suitable temperature, relative humidity, and normal light/dark cycles, standard food and water ad libitum (freely). All animals were left for one month without any treatment to exclude any pregnancy and to ensure that they are devoid from any other drug effect, and aulimation.

The animals were classified into five groups:

1. Group one (Negative control group): Nine (9) female albino rats, which were the blank group in which animals received nothing except normal feeding for three months (90 days).

2. Group two (Positive control group or vehicle control): thirteen (13) female albino rats received $1 \mathrm{ml}$ of the vehicle which was corn oil once daily orally by a curved needle-like oral tube that was introduced directly into stomach (gavage process) for three months (90 days). 
3. Group three: Twenty four (24) female albino rats received BPA compound dissolved in corn oil at a dose $320 \mathrm{mg} / \mathrm{kg} /$ day orally by gavage (which represented 1/10 LD50) for 3 months (90 days). The oral LD50 of BPA in rats was estimated to be about 3200 $\mathrm{mg} / \mathrm{kg}$ body weight (Preethi et al., 2014).

4. Group four: Twenty three (23) female albino rats received BPA compound dissolved in corn oil at a dose 160 $\mathrm{mg} / \mathrm{kg} /$ day orally by gavage (which represent 1/20 LD50) for 3 months (90 days).

5. Group five: Twenty three (23) female albino rats received BPA compound dissolved in corn oil at a dose $80 \mathrm{mg} / \mathrm{kg} /$ day orally by gavage (which represent 1/40 LD50) for 3 months (90 days).

At the end of this period all animals were sacrificed by decapitation using light ether anesthesia after 24 hours of the last dose

Ovaries, uterus and vagina were taken and preserved in $10 \%$ formalin for histopathological examination.

Biochemical analysis: Three $\mathrm{ml}$ blood sample was collected at the beginning and the end of the study from each rat of control and treated rat groups in glass vial (Vacutainer tube) without anticoagulant (5ml capacity). Blood samples were held on ice and serum was obtained by centrifugation of samples at $2000 \mathrm{rpm}$ for 15 minutes within one hour of collection. Serum samples were stored at $-20^{\circ} \mathrm{C}$ until the day of analysis. Serum levels of Follicular Stimulating Hormone (FSH), Luteinizing hormone (LH) and Estrogen
(E2) were determined in female rats of all groups using enzyme-linked immunosorbent assay (ELISA) kits (Diagnostics Systems Laboratories, Webster, TX) according to manufacturer's manual in department of Forensic Medicine and Clinical Toxicology, Faculty of Medicine, Al-Azhar University, Assiut.

Light microscopic examination: The pituitary glands, ovaries, uterus and vagina of all rat groups were fixed in $10 \%$ Formalin. After fixation, the specimens were dehydrated through ascending grades of alcohol, cleared and then embedded in paraffin. Paraffin sections of $5 \mu \mathrm{m}$ thickness were prepared and stained with Hematoxylin and Eosin. The stained sections were examined using light microscope according to Bancroft and Gamble (2002).

\section{Statistical Analysis:}

The collected data were revised, organized, tabulated and statistically analyzed using statistical package for the social sciences (SPSS) version 22.0 for windows. Data are presented as the Mean \pm standard deviation (SD), frequency, and percentage. Continuous normally distributed data were compared by the paired t-test should be used to compare the same group at base line \& after 3 months (two-tailed) and one - way ANOVA test with Bonferroni post hoc test to detect the differences between the studied groups. The level of significance was accepted when $\mathrm{P}$ value $\leq 0.05$. Correlation of resuls after 3 months administration of 3 different doses of BPA was done using Kendall's tau rank correlation test. 


\section{RESULTS}

Concerning positive control and negative control groups, there were no statistical significant differences at baseline and after 3 months of treatment, differences (decrease) among the 3 administered BPA groups between baseline and after three months of BPA administration (Table 1).

whereas there were statistical significant

Table (1): Comparison of serum FSH before and after 3 months administration of the studied groups

\begin{tabular}{|c|c|c|c|}
\hline Studied groups & Base line & After 3 months & P-Value* \\
\hline Positive control, $(\mathrm{N}=13)$ & $0.0206 \pm 0.0015$ & $0.0205 \pm 0.0015$ & $p>0.05$ \\
\hline Negative control, $(\mathrm{N}=9)$ & $0.0204 \pm 0.0015$ & $0.0207 \pm 0.0015$ & $\mathrm{p}>0.05$ \\
\hline LD50 1/10, $(\mathrm{N}=24)$ & $0.0206 \pm 0.0014$ & $0.0159 \pm .00065$ & $\mathrm{p}<0.001$ \\
\hline LD50 1/20, (N=23) & $0.0208 \pm 0.0018$ & $0.0185 \pm 0.002$ & $\mathrm{P}<0.001$ \\
\hline LD50 1/40, $(\mathrm{N}=23)$ & $0.0209 \pm 0.0018$ & $0.0197 \pm .0019$ & $\mathrm{p}<0.05$ \\
\hline $\begin{array}{c}\text { P-Value** } \\
\text { Among all groups }\end{array}$ & \multicolumn{3}{|c|}{$<0.001$} \\
\hline
\end{tabular}

*Independent sample t-test, **F-test (Anova).

Concerning serum FSH after 3 months administration of 3 different doses of $\mathrm{BPA}$, there were negative correlation between BPA dose and serum FSH $\mathrm{mIU} / \mathrm{ml}$ at end of treatment (Table 2 and Figure 1).

Table (2): Correlation of serum FSH after 3 months administration of 3 different doses of BPA

\begin{tabular}{|c|c|c|}
\hline \multirow{2}{*}{$($ FSH $\mathbf{~ m I U / m l )}$} & \multicolumn{2}{|c|}{} \\
\cline { 2 - 3 } & r-value* & P-Value \\
\hline BPA dose & -0.712 & $<0.001$ \\
\hline
\end{tabular}

Kendall's tau rank correlation test.

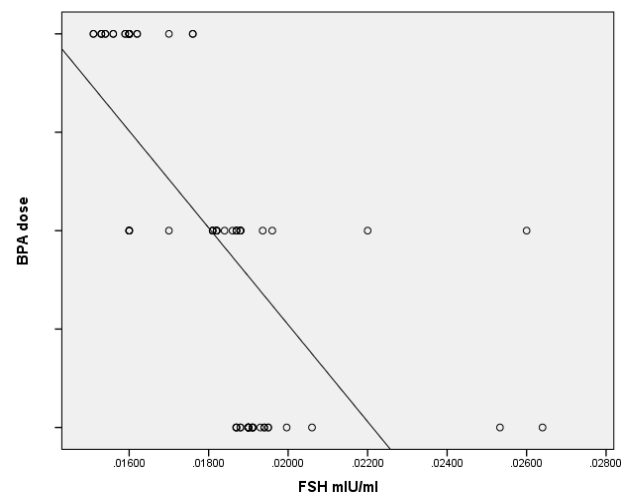

Figure (1): Scatter diagram showing negative correlation between BPA dose and serum FSH $\mathrm{mIU} / \mathrm{ml}$ at end of treatment 
Concerning positive control and negative control groups, there were no statistical significant differences at baseline and after 3 months of treatment, whereas there were statistical significant differences (decrease) among the 3 administered BPA groups between baseline and after three months of BPA administration (Table 3).

Table (3): comparison of serum LH before and after 3 months of the studied groups after administration of BPA

\begin{tabular}{|c|c|c|c|}
\hline $\begin{array}{r}\text { (LH mIU/ml) } \\
(\text { Mean } \pm \text { SD) }\end{array}$ & Base line & After 3 months & P-Value* \\
Studied groups & & & \\
\hline Positive control, $(\mathrm{N}=13)$ & $0.0298 \pm 0.0011$ & $0.0296 \pm 0.0011$ & $\mathrm{p}>0.05$ \\
\hline Negative control, $(\mathrm{N}=9)$ & $0.0295 \pm 0.0011$ & $0.0297 \pm 0.0011$ & $\mathrm{p}>0.05$ \\
\hline LD50 1/10, $(\mathrm{N}=24)$ & $0.0292 \pm 0.0014$ & $0.0222 \pm 0.0006$ & $<0.001$ \\
\hline LD50 1/20, $(\mathrm{N}=23)$ & $0.0296 \pm 0.0015$ & $0.0236 \pm 0.0014$ & $<0.001$ \\
\hline LD50 1/40, $(\mathrm{N}=23)$ & $0.0292 \pm 0.0013$ & $0.0249 \pm .00061$ & $<0.001$ \\
\hline $\begin{array}{l}|l| \\
\text { P-Value }\end{array} * 0.001$ & \\
\hline Among all groups & \multicolumn{3}{|l}{} \\
\hline
\end{tabular}

*Independent sample t-test, **F-test (ANOVA).

Concerning serum LH after 3 months administration of 3 different doses of BPA, there were negative correlation between BPA dose and serum $\mathrm{LH} \mathrm{mIU} / \mathrm{ml}$ at end of treatment (Table 4 and Figure 2).

Table (4): Correlation of serum LH after 3 months administration of 3 different doses of BPA

\begin{tabular}{|c|c|c|}
\hline \multirow{2}{*}{$(\mathbf{L H}$ mIU/ml) } & \multicolumn{2}{|c|}{} \\
\cline { 2 - 3 } BPA dose & r-value* & P-Value \\
\hline & -0.77 & $<0.001$ \\
\hline
\end{tabular}

Kendall's tau rank correlation test, S: Statistically significant difference $(\leq 0.05)$.

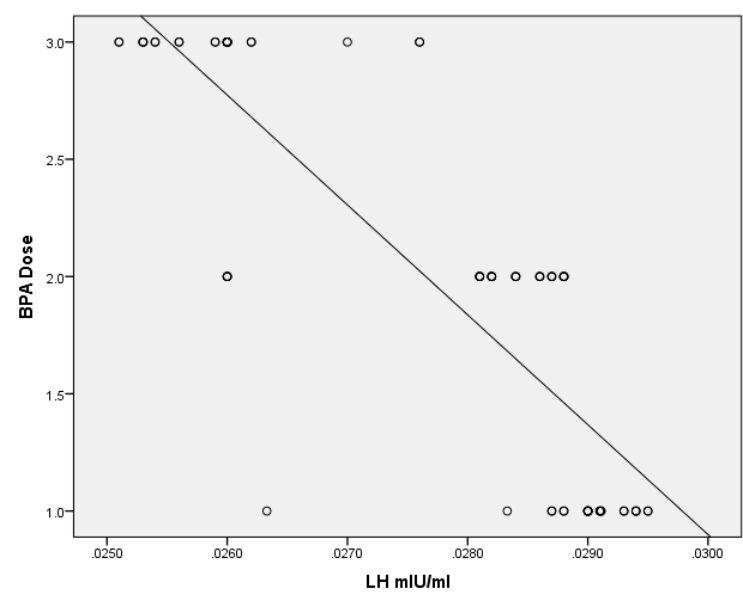

Figure (2): Scatter diagram showing negative correlation between BPA dose and serum $\mathrm{LH} \mathrm{mIU/ml}$ at end of treatment 
Concerning positive control and negative control groups there were no statistical significant differences at baseline and after 3 months of treatment, whereas there were statistical significant differences (decrease) among the 3 administered BPA groups between baseline and after three months of BPA administration, (Table 5).

Table (5): Comparison of serum E2 among studied groups before and after 3 months administration of BPA

\begin{tabular}{|c|c|c|c|}
\hline$\underbrace{(\mathbf{E 2} \mathbf{~ p g} / \mathbf{m l})}_{(\text {Mean } \pm \text { SD })}$ & Base line & After 3 months & P-Value* \\
\hline Studied groups & & & \\
\hline Positive control, $\mathrm{N}=13$ & $87.533 \pm 0.79$ & $87.49 \pm 0.79$ & $p>0.05$ \\
\hline Negative control, $N=9$ & $87.530 \pm 0.79$ & $87.55 \pm 0.79$ & $p>0.05$ \\
\hline LD50 1/10, N=24 & $87.568 \pm 0.89$ & $5.8 \pm 0.73$ & $<0.001$ \\
\hline LD50 1/20, N=23 & $87.146 \pm 1.54$ & $40.3 \pm 2.64$ & $<0.001$ \\
\hline LD50 1/40, $N=23$ & $87.2 \pm 1.7470$ & $50.9 \pm 4.35$ & $<0.001$ \\
\hline $\begin{array}{c}\text { P-Value** } \\
\text { Among all groups }\end{array}$ & \multicolumn{3}{|c|}{$<0.001$} \\
\hline
\end{tabular}

*Independent sample t-test, **F-test (ANOVA).

Concerning serum E2 after 3 months administration of 3 different doses of BPA, there were negative correlation between BPA dose and serum E2 $\mathrm{mIU} / \mathrm{ml}$ at end of treatment (table 6 and figure 3).

Table (6): Correlation of serum E2 after 3 months administration of 3 different doses of BPA

Kendall's tau rank correlation test.

\begin{tabular}{|c|c|c|}
\hline \multirow{2}{*}{$(\mathbf{E} 2 \mathbf{~ p g} / \mathbf{m l})$} & \multicolumn{2}{|c|}{} \\
\cline { 2 - 3 } BPA dose & r- value* & P-Value \\
\hline & -0.79 & $<0.001$ \\
\hline
\end{tabular}

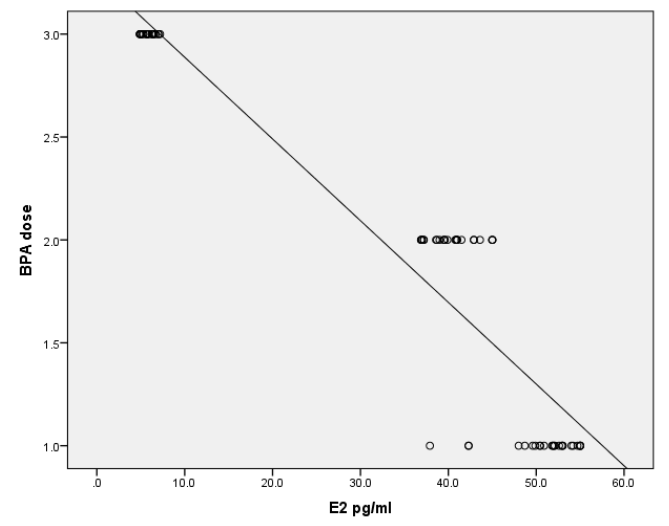

Figure (3): Scatter diagram showing negative correlation between BPA dose and serum E2 pg/ml at end of treatment 
Examination of the ovaries:

1. Control group: The ovary is composed of an outer cortex and inner medulla. The cortex constituted the main and the most important part of the ovary. It contained the ovarian follicles at different stages of growth and development and corpora lutea. The medulla was composed of loose connective tissue rich in blood vessels. The ovarian follicles passed through distinct stages of development including primordial, primary, secondary and mature Graffian follicles (Figure 4 \& 5).

2. BPA treated group: Treatment with different doses of BPA led to obvious histological changes in the structure of the ovaris. In general, there was disruption of the Graafian follicles (Figure 6), and many of the follicles appeared atretic (Figure 7). The medulla showed dilated congested blood vessels and hemorrhage (Figure

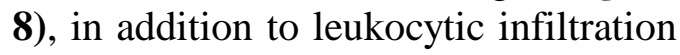
in the interstitial tissue (Figure 9\& 10).

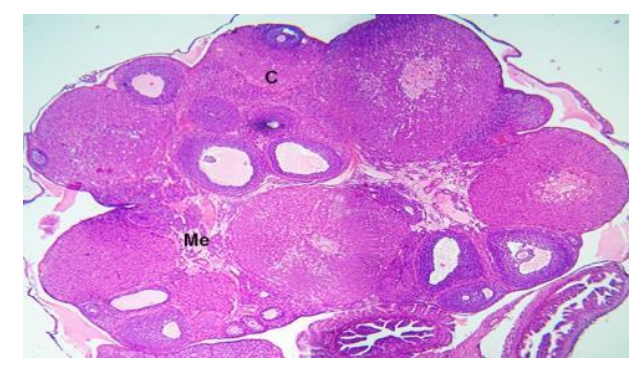

Figure (4): A photograph of a section in the ovary of the control rat group stained with $H$ \& $E$ showing; the cortex $(C)$ containing follicles at different stages of development. The medulla (Me) containing connective tissue and blood vessels. (x 40)

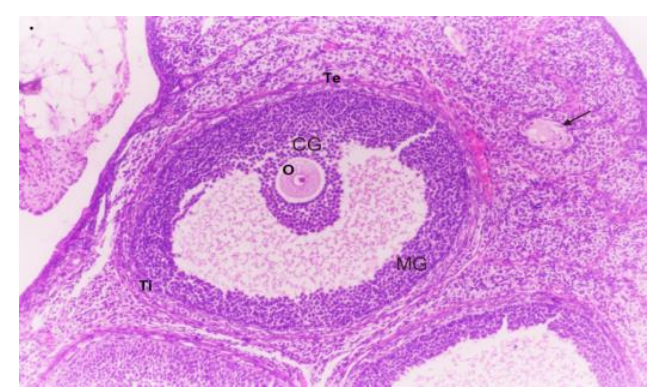

Figure (5): A photograph of a section in the ovary of the control rat group stained with $H \& E$ showing a mature Graffian follicle. The oocyte $(O)$ is surrounded by thick intact cumulus granulosa (CG) cells. Note; the mural granulosa cells (MG) and well developed theca interna (Ti) and externa (Te). An Atritic follicle is observed (arrow). (x 400) 


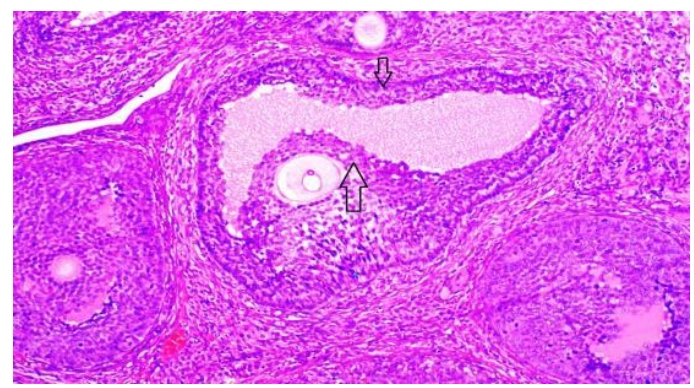

Figure (6): A photograph of a section in the ovary of the 1\10 LD50 BPA treated rat group stained with $\mathrm{H} \& \mathrm{E}$ showing; Disruption of the Graafian follicles (arrow) (x 100)

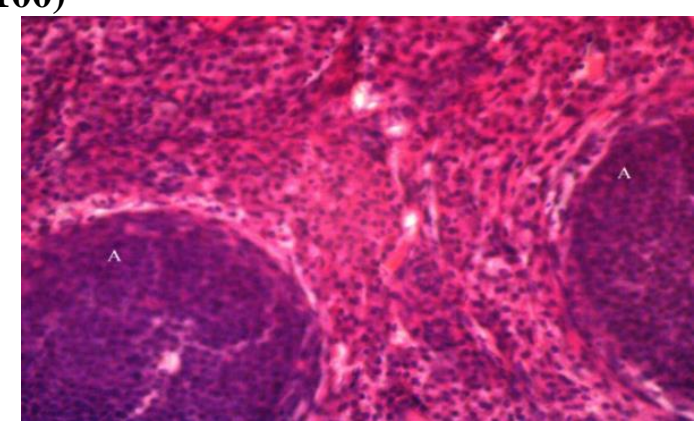

Figure (7): A photograph of a section in the ovary of the 1\10 LD50 BPA treated rat group stained with $\mathrm{H} \& \mathrm{E}$ showing; many atretic follicles (A). (X400)

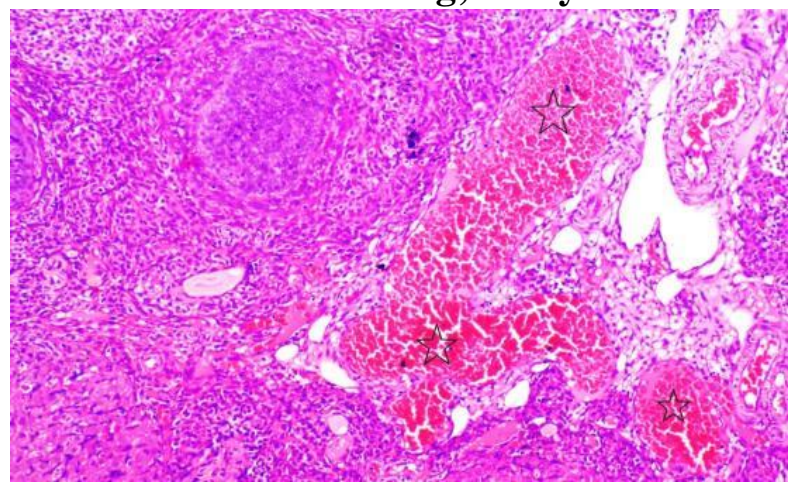

Figure (8): A photograph of a section in the ovary of the 1120 LD50 BPA treated rat group stained with $H \& E$ showing; congested blood vessel and hemorrhage (star). (x 100)

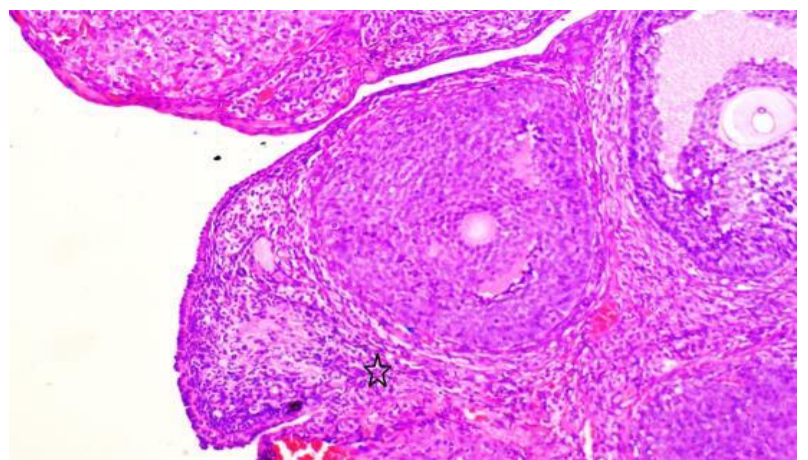

Figure (9): A photograph of a section in the ovary of the 1120 LD50 BPA treated rat group stained with $H \& E$ showing; leukocytic infiltration in the interstitial tissue (star). ( $x$ 100) 


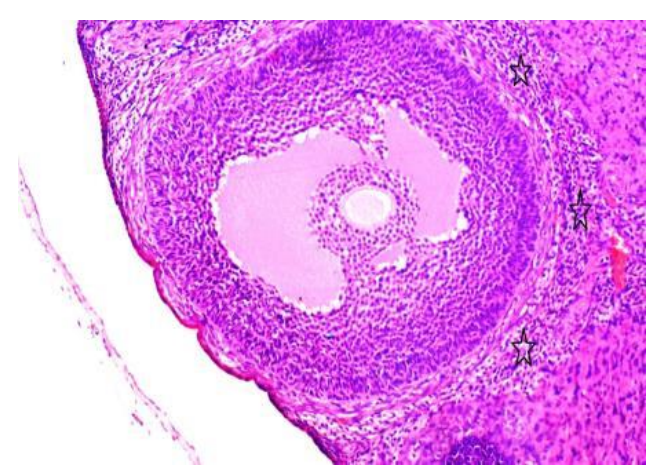

Figure (10): A photograph of a section in the ovary of the $1 \backslash 40$ LD50 BPA treated rat group stained with $\mathrm{H} \& \mathrm{E}$ showing; mild leukocytic infiltration in the interstitial tissue (star). (x 100)

\section{Examination of the Uterus:}

1. Control group: The uterus was composed of two main regions; the outer myometrium and the inner one is the endometrium. The uterus outlined by a simple columnar epithelium (ciliated cells and secretory cells) and an underlying thick connective tissue stroma containing tortuous secretory endometrial glands. The glands extended through the entire thickness of the stroma. The stromal cells of the endometrium were embedded in a network of reticular fibers (Figure 11).
2. BPA treated groups: Treatment with different doses of BPA led to obvious histological changes in the structure of the uterus. In general, there was severe degeneration and necrosis of the surface epithelium (Figure 12), leukocytic infiltration in the interstitial tissue (Figure 13), cystic dilation of endometrial glands and submucosal leukocytic infiltration and hyperplasia of endometrial epithelium (Figure 14), in addition to leukocytic infiltration with vacuolar degeneration in endometrial epithelium (Figure 15).

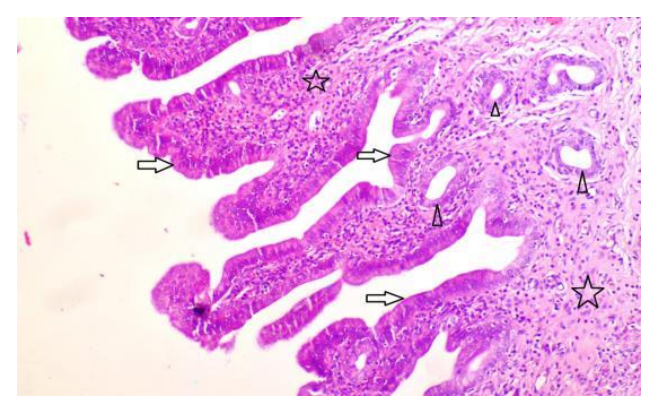

Figure (11): A photograph of a section in the uterus of the control rat group stained with $\mathbf{H} \& \mathbf{E}$ showing; normal histological structure of epithelial lining (arrow), and glandular units (arrowhead) and stromal tissue (star), (x 100) 


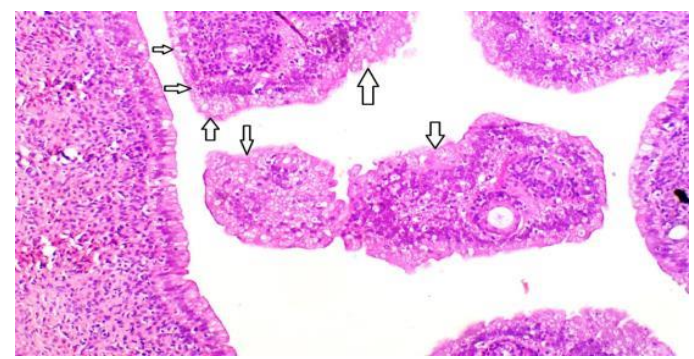

Figure (12): A photograph of a section in the uterus of the 1\10 LD50 BPA treated rat group stained with $H \& E$ showing: Sever degeneration and necrosis of the surface epithelium (arrow) (x 100)

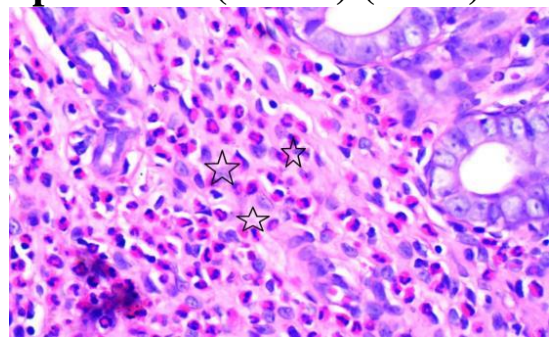

Figure (13): A photograph of a section in the uterus of the 1\10 LD50 BPA treated rat group stained with $H \& E$ showing: sever leukocytic infiltration in the interstitial tissue (star) $(x$ 400)

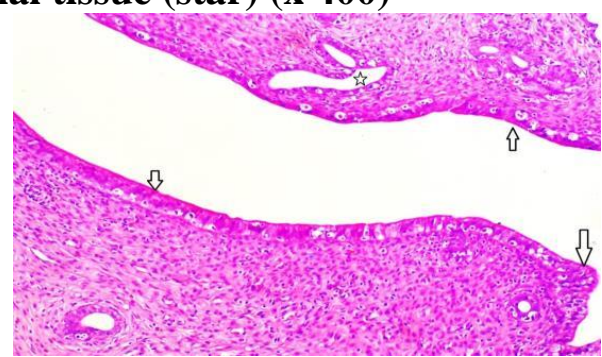

Figure (14): A photograph of a section in the uterus of the 1120 LD50 BPA treated rat group stained with $H \&$ \& showing: cystic dilatation of endometrial glands (star) submucosal leukocytic infiltration and hyperplasia of endometrial epithelium (arrow) (x 100)

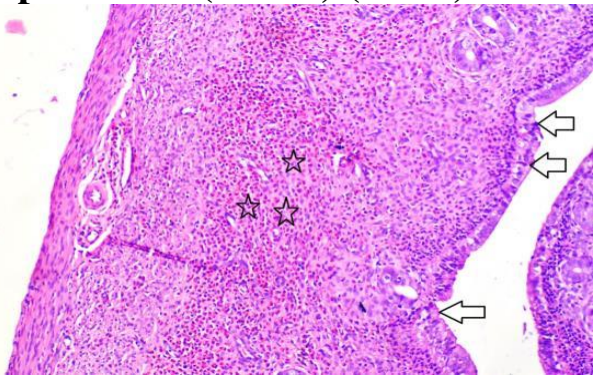

Figure (15): A photograph of a section in the uterus of the 1\40 LD50 BPA treated rat group stained with $H \& E$ showing: Mild degeneration of the surface epithelium (arrow) with sever interstitial leukocytic infiltration (star) (x 100) 


\section{MOHAMED MAHMOUD HUSSEIN et al.,}

Examination of the vagina:

1. Control group: There was normal thickness of vaginal mucosa which is formed of non-keratinised stratified squamous epithelium with underlying vascular connective tissue lamina propria (Figure 16).

2. BPA treated groups: Treatment with different doses of BPA led to obvious histological changes in the structure of the vagina. In general, there was severe keratinization (hyper keratosis) (Figure 17), epithelial atrophy and many cells completely degenerated (Figure 18), in addition to focal patches of decreasing of epithelial lining (Figure 19).

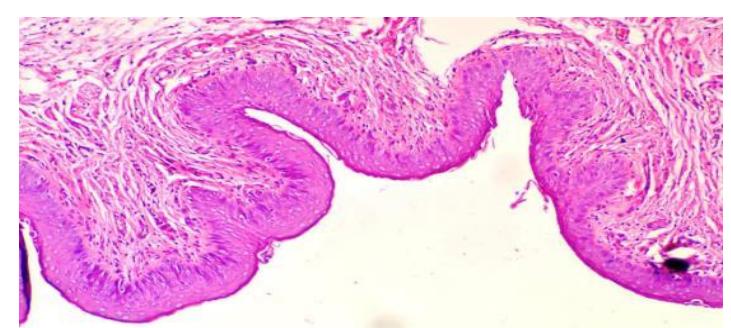

Figure (16): A photograph of a section in the vagina of the control rat group stained with $H \& E$ showing; normal thickness of vaginal mucosa which is formed of non-keratinised stratified squamous epithelium with underlying vascular connective tissue lamina propria. (x 100)

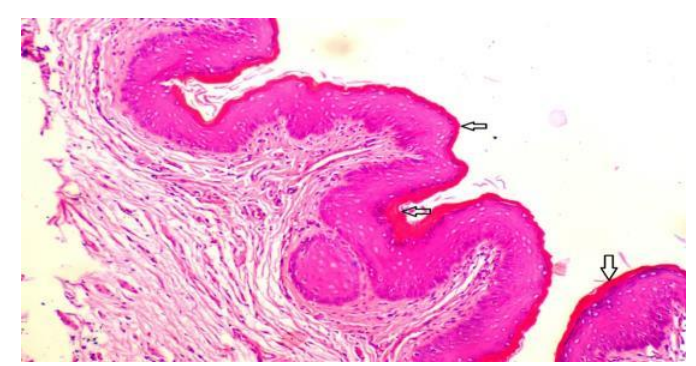

Figure (17): A photograph of a section in the vagina of the $1 \backslash 10$ LD50 BPA treated rat group stained with $H \& E$ showing: sever Keratinization (hyper keratosis) (x 100)

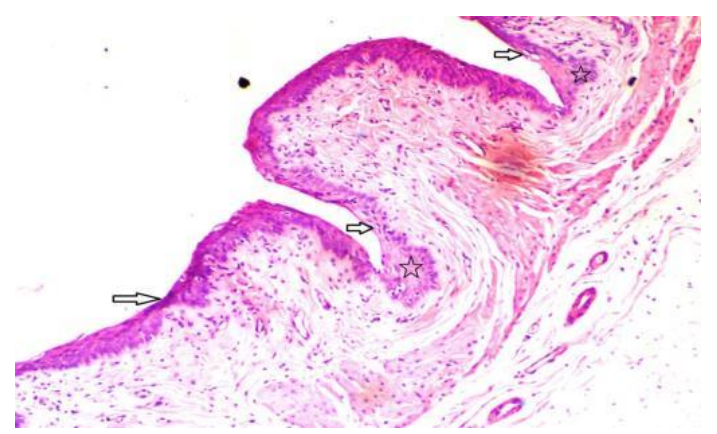

Figure (18): A photograph of a section in the vagina of the 1120 LD50 BPA treated rat group stained with $H \&$ E showing: large areas of epithelial atrophy (arrow) and many cells completely degenerated (star). (x 100) 


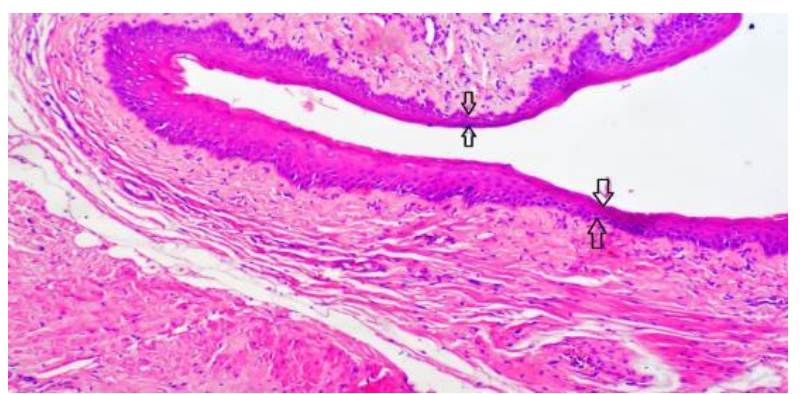

Figure (19): A photograph of a section in the vagina of the $1 \backslash 40$ LD50 BPA treated rat group stained with $\mathrm{H} \& \mathrm{E}$ showing: focal patches of decreasing of epithelial lining (arrow) (x 100)

\section{DISCUSSION}

In this study, rats received BPA by gavage because the oral route is the major route of human exposure to BPA in diet, including ingestion of contaminated food and water (Cichna-Markl, 2012).

The treated rat groups received BPA compound dissolved in corn oil at a dose $320,160,80 \mathrm{mg} / \mathrm{kg} /$ day which represented $1 / 10,1 / 20,1 / 40$ oral LD50 of BPA respectively (Preethi et al., 2014).

In the present study, chronic Bishenol A administration had significantly decreased FSH, LH and estrogen serum levels in adult female rats. Also, there was negative correlation between BPA dose and serum levels of FSH, LH and estrogen at end of treatment.

These results were in agreement with several studies which reported that low and high dose BPA exposure decreased serum FSH, LH and estrogen levels in adult rats and fish compared with controls (Li et al., 2014, Zhou et al., 2014 and Moustafa \& Ahmed 2016).

In rodent studies, perinatal (Xi et al., 2011) and postnatal (Tan et al., 2013) low-dose BPA exposure was reported to increase serum estradiol levels. In contrast, another studies found that although BPA did not alter estradiol levels (Berger et al., 2018), but decreased expression of estrogen receptors (Berger et al., 2010).

In the current work, the histopathological examination of Bisphenol A treated rats showed obvious histological changes in the structure of the ovaries. In general, there was disruption of the Graafian follicles and many of the follicles appeared atretic. The medulla showed dilated congested blood vessels and hemorrhage, in addition to leukocytic infiltration in the interstitial tissue.

These findings were in accordance with other findings from experimental studies indicate that in utero or neonatal low and high dose BPA exposures resulted in abnormal ovarian morphology and histology compared with controls (Ziv-Gal and Flaws 2016). Specifically, BPA exposure increased the number of multi-oocyte follicles (Hunt et al., 2012), inhibited germ cell nest breakdown (Zhang et al., 2012, Wang et al., 2014 and Zhang et al., 2014), decreased the number of primordial follicles (Zhang et al., 2012 and Zhang et al., 2014), increased apoptotic oocytes (Zhang et al., 2014), and increased primordial follicular recruitment (Wang et al., 2014). It also 
affected follicle type distribution by reducing the number of antral follicles and increasing the numbers of primary and secondary follicles (Gámez et al., 2015).

Also, Moustafa and Ahmed (2016) reported that, groups treated with BPA (50 $\mathrm{mg} / \mathrm{kg} \mathrm{b.wt}$.) showed degeneration in the epithelial lining of ovarian follicles, leukocytic infiltration in interstitial tissue and mild congested blood. Groups treated with BPA (200 mg/kg b.wt.) showed congestion, hemorrhage and degenerated ovum. These changes may be due to direct action of BPA in the ovaries due to binding of estrogen receptors (ER) or to indirect effects resulting from alternation in the hypothalamic pituitary unit, or a combination of both (Wetherill et al., 2011).

In the present study, treatment with different doses of BPA led to obvious histological changes in the structure of the uterus of the adult female rats. In general, there was severe degeneration and necrosis of the surface epithelium, leukocytic infiltration in the interstitial tissue, cystic dilatation of endometrial glands and submucosal leukocytic infiltration and hyperplasia of endometrial epithelium, in addition to leukocytic infiltration with vacuolar degeneration in endometrial epithelium.

These results came in harmony with those reported by Moustafa and Ahmed (2016) who found that, groups treated with BPA (50 mg/kg b.wt.) revealed cystic dilation of endometrial gland, submucosal leukocytic infiltration and hyperplasia with invagination of endometrial epithelium. Groups treated with BPA (200 mg/kg b.wt.) showed diffuse leukocytic infiltration with vacuolar degeneration in endometrial epithelium, glandular epithelium and multiple cyst formation in endometrial glands with diffuse interstitial leukocytic infiltration. In this respect, our histopathologicial findings were in agreement with those findings detected by Newbold et al. (2012) who mentioned that BPA has been reported to cause significant histological changes in the reproductive tract. Also, Popa et al. (2014) recorded that histopathologicial changes can be explained by estrogen activity of BPA.

In mice, in utero low dose BPA exposure increased uterine anomalies in the luminal epithelium and glands (Vigezzi et al., 2015) and caused uterine hyperplasia, stromal polyps, and retention of remnants of the Wolffian duct in the adult offspring compared with controls (Newbold et al., 2010 and Newbold et al., 2012). Furthermore, in utero high dose BPA exposure reduced uterine weight in the second generation of pups compared with controls (Hiyama et al., 2011). Neonatal high dose BPA exposure (single dose, $100 \mathrm{mg} / \mathrm{kg}$ ) reduced uterine weight in young adult mice compared to controls (Nah et al., 2011), and neonatal low dose BPA exposure decreased endometrial proliferation in adult ovariectomized rats compared with controls (Bosquiazzo et al., 2010). In young adult rats, low dose BPA exposure from gestation day 6 until weaning increased the thickness of the uterine epithelia and stroma compared with controls (Mendoza et al., 2011). In adult mice, dietary supplementation with low dose BPA resulted in clinical signs that are typical of pyometra (Kendziorski et al., 2012). 
Findings from in vitro studies using various human cell lines indicate that low dose BPA exposure decreased endothelial cell proliferation (Bredhult et al., 2011) and increased decidualized stromal cell proliferation (Mannelli et al., 2015) compared with controls. Similarly, high dose BPA exposure decreased endothelial cell proliferation compared with controls (Ziv-Gal and Flaws, 2016).

In the present study, treatment with different doses of BPA led to histological changes in the structure of the vagina of the adult female rats. In general there was sever keratinization (hyper keratosis), epithelial atrophy and many cells completely degenerated, in addition to focal patches of decreasing of epithelial lining. These results came in harmony with study done by Ahmed et al. (2014) who reported that exposure to BPA both in low environmental and high doses exerted degeneration of the vaginal epithelium with desquamation, hydropic degeneration and pyknosis. With high dose of BPA, there was extensive desquamation in addition to nearby areas of reactive thickening. Also, BPA caused striking changes in vaginal morphology during estrus, including a decrease in the thickness of the epithelial layer (Schönfelder et al., 2010). Contrary to the current work, mice exposed prenatally to BPA did not show vaginal or uterine changes (Suzuki et al., 2010). Lee et al. (2018) found that monitoring changes in the vaginal epithelium of adult rats was the least effective method for detecting oestrogenic activity for BPA. The discrepancy of the results may be referred to different models of animal studied.
Estrogens stimulate vaginal epithelium proliferation in vivo and play a critical role in vaginal growth, epithelial morphogenesis, cyto-differentiation, and secretory activity. The role of Estrogen receptor is studied as a probable key of how it induces proliferative changes in the vagina that promote to carcinomatous changes. ER $\alpha$ localizes both nuclear and intracytoplasmic (Raso et al., 2011). In utero, exposure of rats to low doses of BPA, similar to amounts typically found in the environment, elicits long-term changes in ER $\alpha$ expression (Khurana et al., 2010). BPA significantly downregulates their expression, leading to striking morphologic changes in the differentiation and cornification of vagina (Schönfelder et al. 2010). Estrogen receptor $\alpha(E R \alpha)$ down-regulation seems to be responsible for the observed altered vaginal morphology (Ahmed et al. 2014).

\section{CONCLUSION}

There were chronic toxic effects of BPA on the female reproductive system. So the exposure to BPA that present in plastic containers and other products produces toxic effect on the reproductive health of females.

\section{REFERENCES}

1. Ahmed RAM, El Ghamrawy TA and Salama EEA. (2014): Effect of prenatal exposure to bisphenol a on the vagina of albino rats: immunohistochemical and ultrastructural study. Folia Morphologica., 73(4): 399-408.

2. Bancroft JD and Gamble M. (2002): Theory and Practice of Histological Technique. (5th edition), Pbl. Churchill Livingstone, Edinburg, London. Pp. 130155. 
3. Berger K, Eskenazi B, Kogut K, Parra K, Lustig RH, Greenspan LC, Holland N, Calafat AM, Ye X and Harley KG. (2018): Association of prenatal urinary concentrations of phthalates and bisphenol a and pubertal timing in boys and girls. Environmental Health Perspectives, 126 (9):97-104.

4. Berger RG, Foster WG and deCatanzaro D. (2010): Bisphenol-A exposure during the period of blastocyst implantation alters uterine morphology and perturbs measures of estrogen and progesterone receptor expression in mice. Reproductive Toxicology, 30(3): 393-400.

5. Bosquiazzo VL, Varayoud J, Muñoz-deToro M, Luque E.H and Ramos JG. (2010): Effects of Neonatal Exposure to Bisphenol A on Steroid Regulation of Vascular Endothelial Growth Factor Expression and Endothelial Cell Proliferation in the Adult Rat Uterus1. Biology of Reproduction, 82(1): 86-95.

6. Braun JM, Kalkbrenner AE, Calafat AM, Bernert JT, Ye X, Silva MJ, Barr DB, Sathyanarayana $S$ and Lanphear BP. (2011): Variability and predictors of urinary Bisphenol A concentrations during pregnancy. Environmental Health Perspectives, 119 (1): 131-137.

7. Bredhult $C$, Sahlin $L$ and Olovsson $M$. (2011): Gene expression analysis of human endometrial endothelial cells exposed to Bisphenol A. Reproductive Toxicology, 28(1): 18-25.

8. Chapin R, Adams J, Boekelheide K, Gray L, Hayward SW, Lees PS, McIntyre BS, Portier K, Schnorr T, Selevan S, Vandenbergh JG and Woskie RS (2011): NTP-CERHR Expert Panel Report on the Reproductive and Developmental Toxicity of Bisphenol A. Birth Defects Research (Part B) Developmental and Reproductive Toxicology, 83(3):157-395.
9. Cichna-Markl M. (2012): Sample cleanup by sol-gel immunoaffinity chromatography for the determination of bisphenol A in food and urine. Methods, 56(2):186-191.

10.Ćwiek-Ludwicka $K$ and Ludwicki JK. (2014): Endocrine Disruptors in Food Contact Materials; Is There a Health Threat? Roczniki Panstwowego Zakladu. Higieny, 65(3):169-177.

11.Gámez JM, Penalba R, Cardoso N, Bernasconi P. S, Carbone S, Ponzo O and Reynoso R. (2015): Exposure to a low dose of bisphenol A impairs pituitaryovarian axis in prepubertal rats. Environmental Toxicology and Pharmacology, 39(1): 9-15.

12.Geens $T$, Goeyens $L$ and Covaci $A$. (2011): Are potential sources for human exposure to Bisphenol-A overlooked? International Journal of Hygiene and Environmental Health, 214(5): 339-347.

13.Hiyama M, Choi EK, Wakitani S, Tachibana T, Khan H, Kusakabe K.T and Kiso Y. (2011): Bisphenol-A (BPA) Affects Reproductive Formation across Generations in Mice. Journal of Veterinary Medical Science, 73(9): 1211-1215.

14.Kendziorski JA, Kendig EL, Gear RB, and Belcher SM (2012): Strain specific induction of pyometra and differences in immune responsiveness in mice exposed to $17 \alpha$-ethinyl estradiol or the endocrine disrupting chemical bisphenol A. Reproductive Toxicology, 34(1): 22-30.

15.Khurana S, Ranmal $S$ and BenJonathan N. (2010): Exposure of Newborn Male and Female Rats to Environmental Estrogens: Delayed and Sustained Hyperprolactinemia and Alterations in Estrogen Receptor Expression1. Endocrinology, 141(12): 4512-4517. 
16.Lee J, Choi K, Park J, Moon HB, Choi G, Lee JJ, Suh E, Kim H, Eun S, Kim G, Cho GJ, Kim SK, Kim S, Kim SY, Kim S, Eom S, Choi S, Kim YD and Kim S. (2018): Bisphenol A distribution in serum, urine, placenta, breast milk, and umbilical cord serum in a birth panel of motherneonate pairs. Science of the Total Environment, 626: 1494-1501.

17.Li Y, Zhang W, Liu J, Wang W, Li H, Zhu $J$ and Wu T. (2014): Prepubertal bisphenol A exposure interferes with ovarian follicle development and its relevant gene expression. Reproductive Toxicology, 44: 33-40.

18.Mannelli C, Szóstek AZ, Lukasik K, Carotenuto C, Ietta F, Romagnoli R, Ferretti C, Paulesu L, Wolczynski S. and Skarzynski DJ. (2015): Bisphenol A modulates receptivity and secretory function of human decidual cells: an in vitro study. Reproduction, 150(2): 115125.

19.Mendoza CA, García-Guzmán $M$, Baranda-Avila N, Morimoto S, PerrotApplanat $M$ and Cerbón M. (2011): Administration of bisphenol A to dams during perinatal period modifies molecular and morphological reproductive parameters of the offspring. Reproductive Toxicology, 31(2): 177-183.

20.Mirmira P and Evans-Molina C. (2014): Bisphenol A, obesity, and type 2 diabetes mellitus: genuine concern or unnecessary preoccupation? Translational Research, 164(1):13-21.

21.Moustafa GG and Ahmed AA. (2016): Impact of prenatal and postnatal exposure to bisphenol A on female rats in a two generational study: Genotoxic and immunohistochemical implications. Toxicology Reports, 3:685-695.

22.Nah WH, Park MJ and Gye MC. (2011): Effects of early prepubertal exposure to bisphenol A on the onset of puberty, ovarian weights, and estrous cycle in female mice. Clinical and Experimental Reproductive Medicine, 38(2):75-81.

23.Newbold RR, Jefferson WN and PadillaBanks E. (2010): Long-term adverse effects of neonatal exposure to bisphenol A on the murine female reproductive tract. Reproductive Toxicology, 24(2): 253-258.

24.Newbold RR, Jefferson WN and PadillaBanks E. (2012): Prenatal Exposure to Bisphenol A at Environmentally Relevant Doses Adversely Affects the Murine Female Reproductive Tract Later in Life. Environmental Health Perspectives, 117(6): 879-885.

25.Peretz J, Vrooman L, Ricke WA, Hunt PA, Ehrlich S, Hauser $\mathbf{R}$ and Padmanabhan V. (2014): Bisphenol A and reproductive health: update of experimental and human evidence, 20072013. Environmental Health Perspectives, 122:775-786.

26.Popa DS, Bolfa $P$, Kiss $B$, Vlase $L$, P`altinean R, Pop A, C`atoi C, Cris G and Loghin F. (2014): Influence of Genista Tinctoria L or Methylparaben on Subchronic Toxicity of Bisphenol A in Rats. Biomedical and Environmental Sciences, 27(2):85-96.

27.Preethi S, Esther LD and Sreedevi B. (2014): Toxicity Studies of Bisphenol-A Induced Sprague Dawley Rats. International Journal of Pharmacy and Pharmaceutical Research. 2:1-6.

28.Raso MG, Behrens C, Herynk M.H, Liu S, Prudkin L, Ozburn NC, Woods DM, Tang X, Mehran RJ, Moran JJ and Wistuba II (2011): Immunohistochemical Expression of Estrogen and Progesterone Receptors Identifies a Subset of NSCLCs and Correlates with EGFR Mutation. Clinical Cancer Research, 15(17): 53595368. 
29.Rubin BS. (2011): Bisphenol A: An endocrine disruptor with widespread exposure and multiple effects. Journal of Steroid Biochemistry \& Molecular Biology, 127(1-2): 27-34.

30.Schönfelder G, Flick B, Mayr E, Talsness C, Paul M. and Chahoud I. (2010): In Utero Exposure to Low Doses of Bisphenol A Lead to Long-term Deleterious Effects in the Vagina. Neoplasia., 4(2): 98-102.

31.Suzuki A, Sugihara A, Uchida K, Sato T, Ohta Y, Katsu Y, and Iguchi T. (2010): Developmental effects of perinatal exposure to bisphenol-A and diethylstilbestrol on reproductive organs in female mice. Reproductive Toxicology, 16(2): 107-116.

32.Tan W, Huang H, Wang Y, Wong TY, Wang CC. and Leung LK. (2013): Bisphenol A differentially activates protein kinase $\mathrm{C}$ isoforms in murine placental tissue. Toxicology and Applied Pharmacology, 269(2): 163-168.

33.Vigezzi L, Bosquiazzo VL, Kass L, Ramos JG, Muñoz-de-Toro M, and Luque EH. (2015): Developmental exposure to bisphenol A alters the differentiation and functional response of the adult rat uterus to estrogen treatment. Reproductive Toxicology, 52: 83-92.

34.Wang $X$, Chang F, Bai Y, Chen F, Zhang J and Chen L. (2014): Bisphenol A enhances kisspeptin neurons in anteroventral periventricular nucleus of female mice. Journal of Endocrinology, 221(2): 201-213.

35. Wetherill YB, Akingbemi BT, Kanno J, McLachlan JA, Nadal A, Sonnenschein C, Watson HC, Zoelleri $R$ and Belcher SM. (2011): In vitro molecular mechanisms of bisphenol A action. Reproductive Toxicology, 24(2): 178-198.
36.Xi W, Lee CK, Yeung WS, Giesy JP, Wong MH, Zhang $X$ and Wong CK. (2011): Effect of perinatal and postnatal bisphenol A exposure to the regulatory circuits at the hypothalamus-pituitarygonadal axis of CD-1 mice. Reproductive Toxicology, 31(4):409-417.

37.Zhang HQ, Zhang XF, Zhang LJ, Chao HH, Pan B, Feng YM and Shen W. (2012): Fetal exposure to bisphenol A affects the primordial follicle formation by inhibiting the meiotic progression of oocytes. Molecular Biology Reports, 39(5): 5651-5657.

38.Zhang T, Li L, Qin X.S, Zhou Y, Zhang XF, Wang LQ and Shen W. (2014): Di(2-ethylhexyl) phthalate and bisphenol A exposure impairs mouse primordial follicle assembly in vitro. Environmental and Molecular Mutagenesis, 55(4): 343-353.

39.Zhou J, Qu F, Jin Y. and Yang DX. (2014): The extracts of Pacific oyster (Crassostrea gigas) alleviate ovarian functional disorders of female rats with exposure to bisphenol a through decreasing FSHR expression in ovarian tissues. African Journal of Traditional, Complementary, and Alternative Medicines, 11(5):1-7.

40.Ziv-Gal A and Flaws JA. (2016): Evidence for bisphenol A-induced female infertility: a review (2007-2016). Fertility and Sterility, 106(4): 827-856. 
در اسة هستوباثولوجية وبيوكيميائية عن الإعطاء المزمن لمادة

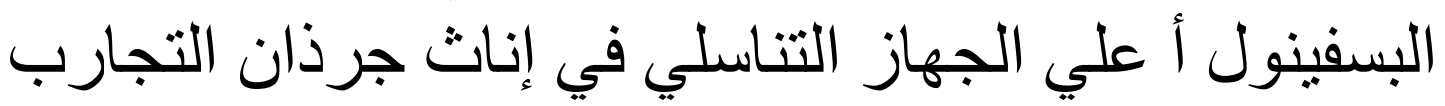
البيضاء

محمد محمود حسين, فؤاد حلمى الدباح, محمد فتحي عساسة, السيد محمد تعيلب*, محمد علي عبدالحميد

قسمي الطب الثرعى و السموم الإكلينيكية, والباتولوجيا العامةث*، كلية الطب, جامعة الأزهر

E-mail: mohamedhussein_122@gmail.com

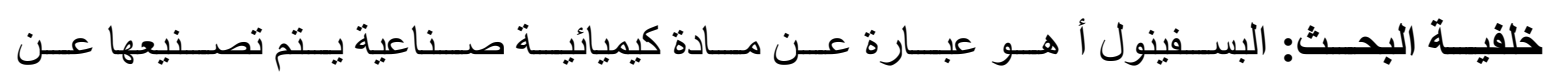

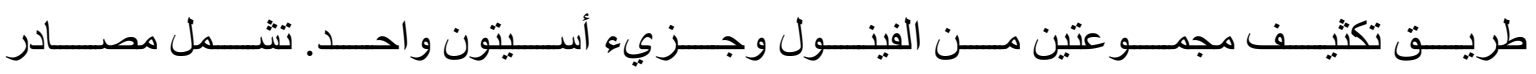

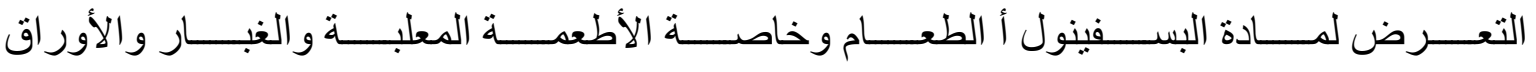

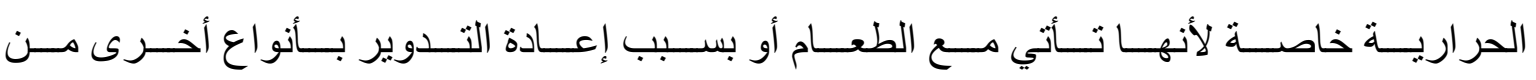
الورق ومو اد طب الأسنان و الأجهزة الطبية وتطبيقات الرعاية الصحية.

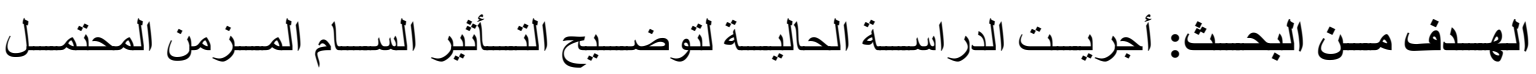

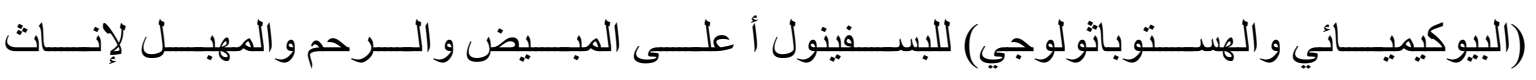

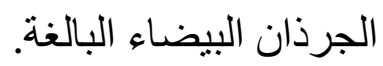

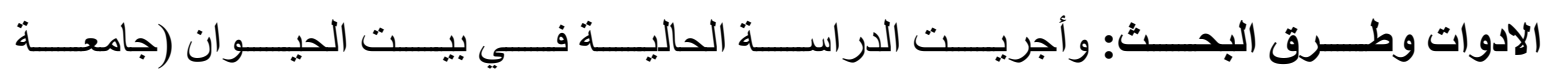

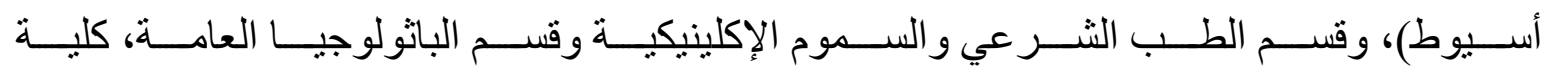

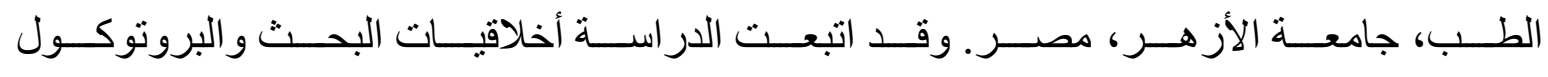

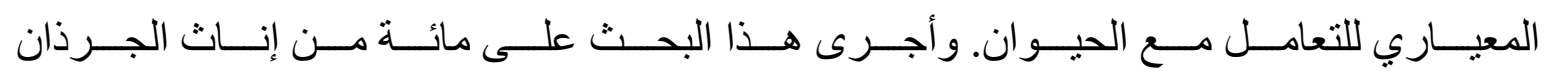

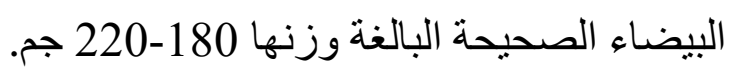

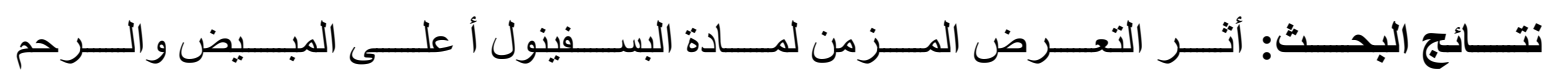

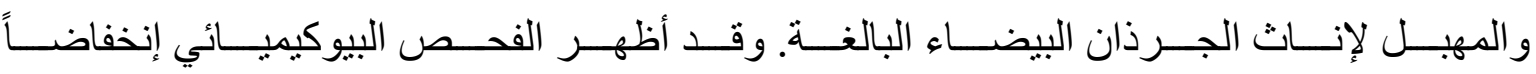

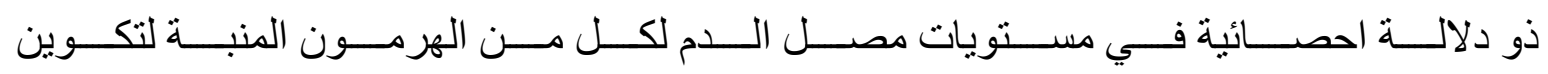

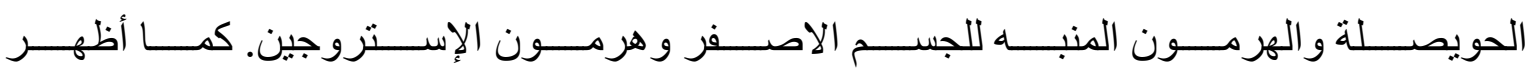

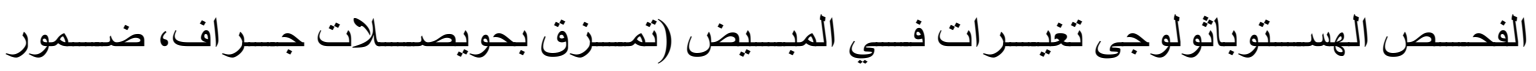




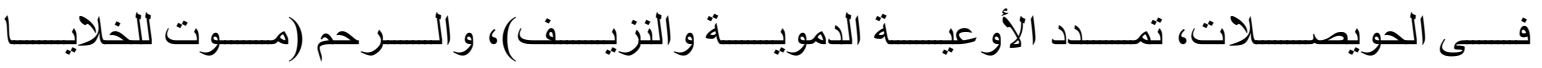

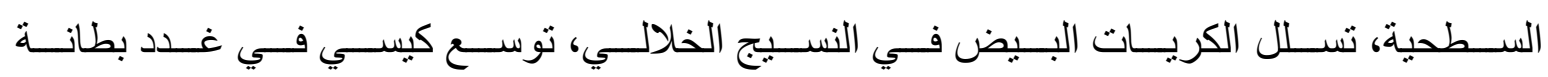

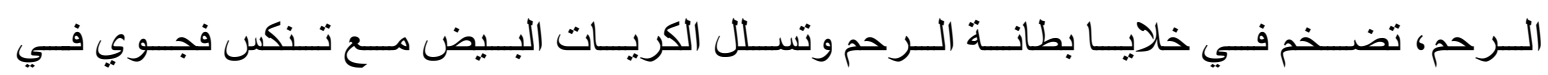

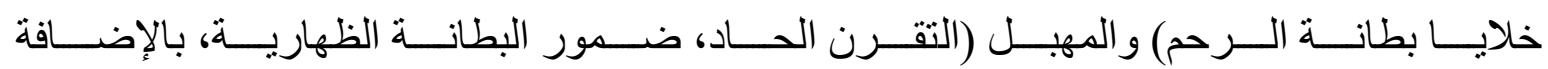

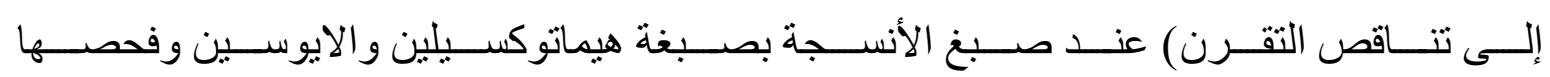
باستخدام المجهر الضوئي.

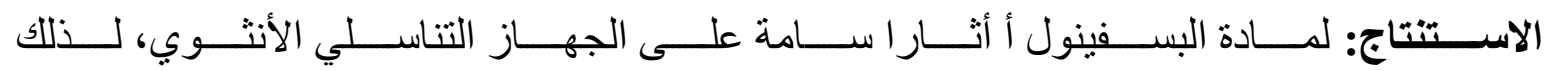

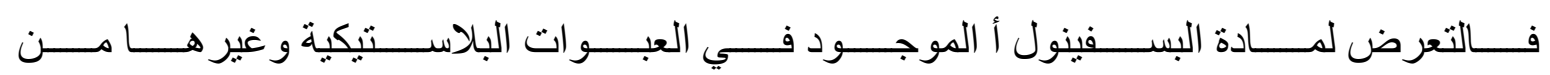
المنتجات ينتج عنه تأثير ا ساما على الصحة الإنجابية للإناث. الكلمات الدالة: مادة البسفينول، الجهاز التناسلى، إناث جرذان التجارب البيضاء. 